\title{
PANDEMIA, ECONOMÍA Y POLÍTICAS MULTINIVEL. LOS CASOS DE LAS PROVINCIAS \\ DE CHACO Y CORRIENTES
}

\section{PANDEMIC, ECONOMICS AND MULTILEVEL POLICIES. THE CASES OF THE PROVINCES OF CHACO AND CORRIENTES}

\author{
Lucas Ferrero \\ Facultad de Ciencias Económicas \\ Universidad Nacional del Nordeste \\ Resistencia, Chaco, Argentina \\ lucasferrero@gmail.com
}

\author{
Carlos Matías Hisgen \\ Facultad de Ciencias Económicas \\ Universidad Nacional del Nordeste \\ Resistencia, Chaco, Argentina \\ mhisgen@gmail.com
}

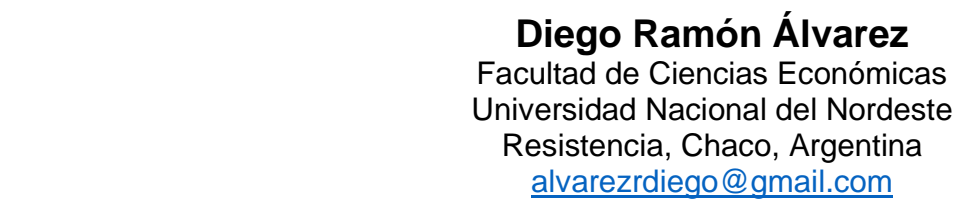

Fecha de recepción: 27/09/2020 - Fecha de revisión: 15/12/2020 - Fecha de aprobación: 31/12/2020

DOI: https://doi.org/10.36995/j.visiondefuturo.2021.25.02.002.es

\section{RESUMEN}

Existen dificultades en tiempo real para mejorar la comprensión del fenómeno epidemiológico COVID-19, de su interacción con variables sociales, económicas, y con las respuestas adecuadas de política pública. El objetivo principal de este trabajo es responder a estas necesidades en el contexto de emergencia para contribuir a mejorar las capacidades de resiliencia del sistema socioeconómico regional. Para ello, adaptamos, integramos y extendemos marcos referenciales utilizados en aplicaciones al caso actual con los siguientes pilares: a) Sistemas y modelos socioeconómicos (econométricos y calibrados); b) Sanitariosepidemiológicos (SEIR); c) Determinación de políticas óptimas sociales, sectoriales y sanitarias, basados en adaptaciones de modelos de economía del sector público; d) Criterios establecidos y en desarrollo para identificar segmentaciones y fuentes de heterogeneidad relevantes en función de flexibilidad contractual, categoría "social" de la actividad, segmentación socioeconómica, ubicación y tamaño, entre otros, que contribuyan a determinar variaciones en costos y beneficios sociales y espacios de mejoras en las políticas públicas aplicadas. Los resultados son de utilización práctica, como la realización de pronósticos de evolución condicionada de variables epidemiológicas, sociales, y por actividad, así como para la determinación de escenarios de estrés relevantes para el diseño de políticas de contingencias. Los desarrollos corresponden a las provincias de Corrientes y de Chaco que, al momento, presentan dinámicas epidemiológicas marcadamente diferentes.

\footnotetext{
"Visión de Futuro" Año 18, Volumen N²5 N², Edición Especial-III Congreso Regional de Economía del Norte Grande-Pág 31-55 URL de la Revista: http://visiondefuturo.fce.unam.edu.ar/index.php/visiondefuturo/index URL del Documento: https://visiondefuturo.fce.unam.edu.ar/index.php/visiondefuturo/issue/view/20 ISSN 1668 - 8708 - Versión en Línea E-mail: revistacientifica@fce.unam.edu.ar

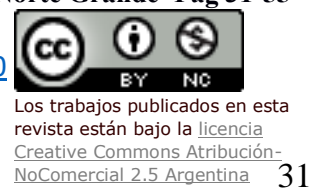


PALABRAS CLAVE: COVID-19; Economía; Políticas; Chaco; Corrientes.

\section{ABSTRACT}

There are difficulties in improving in real time the understanding of the epidemiological phenomenon COVID-19, its interaction with social and economic variables, and with the appropriate public policy responses. The main objective of this work is to contribute to a betterment in the resilience capacities of the regional socioeconomic system, in the present emergency context. To do it, we adapt, integrate and extend the following conceptual and empirical frameworks: a) Socio-economic systems and models (econometric and calibrated); b) Sanitary-epidemiological (SEIR); c) Optimal social, sectoral and health policies, based on adaptations of public sector economic models; d) Criteria, both established and under current development, which identify relevant segmentations and sources of heterogeneity, based on contractual flexibility, "social" category of the activity, socioeconomic segmentation, location and size, among others, that, in turn, contribute to determining variations in costs and social benefits. The results are for practical use, such as forecasting the conditional evolution of epidemiological, social, and activity variables, as well as for determining relevant stress scenarios for the design of contingency policies. The developments correspond to the provinces of Corrientes and Chaco, which, at present, exhibit markedly different epidemiological dynamics.

KEY WORDS: COVID-19; Economics; Policies; Chaco; Corrientes.

\section{INTRODUCCIÓN}

El brote de la enfermedad por coronavirus de 2019 (COVID-19) se ha convertido en una emergencia de salud pública de preocupación internacional. El número de individuos infectados con COVID y muertes relacionadas continúan aumentando.

Una de las dificultades centrales en términos de la pandemia se refiere a la incertidumbre sobre los parámetros epidemiológicos relevantes. Esto ha provocado que la reacción inicial (principal) desde la política pública hayan sido las medidas de aislamiento y cierre de actividades. Posteriormente, los países han ido cambiando y ajustando medidas, de acuerdo con la evolución epidemiológica, socioeconómica, la capacidad estatal y valoraciones sociales y de los líderes gubernamentales.

Este trabajo resume una agenda vigente, enfocada en mejorar la calidad de los sistemas de información utilizables a nivel subnacional y en detectar espacios de mejoras en las

\footnotetext{
“Visión de Futuro" Año 18, Volumen N²5 N² 2, Edición Especial-III Congreso Regional de Economía del Norte Grande-Pág 31-55 URL de la Revista: http://visiondefuturo.fce.unam.edu.ar/index.php/visiondefuturo/index

URL del Documento: https://visiondefuturo.fce.unam.edu.ar/index.php/visiondefuturo/issue/view/20

ISSN 1668 - 8708 - Versión en Línea

E-mail: revistacientifica@fce.unam.edu.ar
} 
políticas de los tres niveles de gobierno que, directa o indirectamente, tienen incumbencia en áreas de políticas públicas relacionadas.

En la Sección 2 se presenta un breve resumen de la aproximación seguida en el resto del trabajo, como forma de articulación de temas en función del objetivo integral de la agenda. En la Sección 3 se abordan aspectos epidemiológicos y de la evolución del distanciamiento, y presentan algunos componentes de impacto económico y fuentes de heterogeneidad espacial, por actividades, ocupacionales y socioeconómicas, que permiten detectar espacios de intervención focalizadas. Finalmente, en la Sección 4, se incluye una revisión de aspectos de economía del comportamiento, como otro espacio de la agenda destinada a mejorar la eficacia de las políticas públicas. La última sección, presenta algunas conclusiones.

\section{DESARROLLO}

\section{Encuadre teórico y agenda}

Las características epidemiológicas presentan dificultades en la práctica para la estimación. Especialmente porque los errores y sesgos de medición son inevitables. Una ventaja de las medidas de aislamiento extremas es que permite más tiempo para reducir el nivel de incertidumbre acerca de parámetros relevantes del proceso y de las características locales y regionales asociadas.

Los esfuerzos de medición intentan mejorar nuestra comprensión sobre las posibilidades de reducción de costos sociales desde la organización social y las políticas públicas, dadas las características del proceso pandémico y los instrumentos disponibles. Esto incluye evaluar mejoras posibles por sobre la definición de políticas uniformes iniciales, que incluye el confinamiento extremo.

El proceso epidemiológico encuentra una estructura que reacciona desde lo individual y grupal, en función de la percepción de riesgos percibidos, y desde el sistema político institucional, con medidas de política pública. El canal entonces opera desde la Epidemia $\rightarrow$ reacciones (sociales, conductuales y de políticas) $\rightarrow$ Desempeño (sanitario, socioeconómico, político).

$$
\text { Shock epidemiológico }\left\{\begin{array}{c}
\text { Respuestas de conductas } \\
\text { Respuestas de política pública }
\end{array}\right.
$$

Una vez activado, el proceso se convierte en un sistema de interdependencias, con los siguientes componentes:

\footnotetext{
"Visión de Futuro" Año 18, Volumen No 25 No 2, Edición Especial-III Congreso Regional de Economía del Norte Grande-Pág 31-55 URL de la Revista: http://visiondefuturo.fce.unam.edu.ar/index.php/visiondefuturo/index

URL del Documento: https://visiondefuturo.fce.unam.edu.ar/index.php/visiondefuturo/issue/view/20

ISSN 1668 - 8708 - Versión en Línea

E-mail: revistacientifica@fce.unam.edu.ar
} 


$$
\left(\begin{array}{c}
\text { Epidemiología } \\
\text { Conducta } \\
\text { Políticas }
\end{array}\right) \rightarrow \text { Territorio } \rightarrow \text { Desempeños }\left(\begin{array}{c}
\text { Epidemiológicos } \\
\text { Socioeconómicos } \\
\text { Reacciones de política }
\end{array}\right)
$$

Desde el punto de vista epidemiológico, los modelos SEIR son los más utilizados para esquematizar, cuantificar y simular aspectos relevantes (Stock 2020; Fernandez-Villaverde y Jones 2020). Su denominación varía, pero se refiere a los componentes principales: la población susceptible de ser contagiada (S), la población expuesta al contagio (E), la población infectada (I), y la población retirada del proceso epidemiológico $(R)$, que puede ser recuperada inmunizada o no, y fallecida. La mayor parte de los tratamientos incluso en economía hacen pie en este tipo de modelos, donde la dinámica de interacción entre los cuatro componentes es central para determinar las características de "las curvas", el estrés de capacidades del sistema de salud, y los riesgos generales sobre una determinada jurisdicción (Glover y otros, 2020).

Una aproximación difundida más o menos explícita, es intentar entender y posteriormente intervenir para afectar estas interacciones, a partir de las características de segmentos y su grado de vulnerabilidad en cada eslabón. Es decir, los conjuntos (S, E, I) presentan segmentaciones relevantes desde el punto de vista epidemiológico, socioeconómico y de políticas públicas.

Por ejemplo, se puede pensar en segmentaciones desde el punto de vista de políticas: cohortes de edad y comorbilidades, intensidad del problema epidemiológico localizado, grado de transmisión comunitaria, estatus de vulnerabilidad social y de ingresos, tipo de actividad laboral, situación empresarial y del empleo.

Este proceso de partición puede ser jerarquizado. La primera jerarquía de partición puede ser geográfica, dada la enorme heterogeneidad de densidad demográfica y tecnologías asociadas en la interacción social. Otra basada en criterios epidemiológicos de vulnerabilidad y riesgos, por ejemplo, por cohortes de edad. Cada componente presenta complejidades propias del fenómeno y desafíos específicos asociados a su medición e integración. Por ejemplo, la población más vulnerable en términos de edad es la de los adultos mayores, por lo que el riesgo de muerte relevante en la segmentación; pero el proceso de contagios en $\mathrm{E}$ presenta riesgos en los niños y jóvenes en edad escolar y/o universitaria, entendiendo que la sintomatología es menos agresiva y puede pasar inadvertida. No así, el riesgo de contagio y propagación.

El tratamiento uniforme, en ambos extremos, implica que segmentos quedarán expuestos innecesariamente a riesgos diversos (salud, económicos). Esta aproximación es central en el trabajo influyente de Acemoglu et al (2020). La intención de apartarse del

\footnotetext{
"Visión de Futuro" Año 18, Volumen No 25 No 2, Edición Especial-III Congreso Regional de Economía del Norte Grande-Pág 31-55 URL de la Revista: http://visiondefuturo.fce.unam.edu.ar/index.php/visiondefuturo/index

URL del Documento: https://visiondefuturo.fce.unam.edu.ar/index.php/visiondefuturo/issue/view/20

ISSN 1668 - 8708 - Versión en Línea

E-mail: revistacientifica@fce.unam.edu.ar
} 
tratamiento homogéneo implica reconocer las heterogeneidades relevantes en base a distintos criterios de partición.

La idea de costos sociales y su minimización tienen contrapartes concretas en el nivel de estrés sobre el sistema social en su conjunto. A medida que aumenta la exposición, el aislamiento y la destrucción de ingresos y riqueza, los contagios y decesos, las demandas sectoriales y tensiones sobre el sistema social, político-institucional son crecientes.

Otro aspecto distintivo de la heterogeneidad se refiere a la capacidad estatal en sus distintos niveles de gobierno (federal, provincial, y local) y de sus jurisdicciones horizontales con incumbencia (salud, policía, social, educativa), para adaptarse, reconocer las problemáticas y responder adecuadamente. Esto incluye la capacidad para coordinar y complementar niveles y jurisdicciones en pos de un objetivo común. Las orientaciones políticoclientelares, la rigidez fiscal, las deficiencias reputacionales y las condiciones socioeconómicas y culturales implican costos enormes que no se distribuyen de forma homogénea, incluso en sus implicancias sobre los procesos de inclusión y construcción de capital humano y social. Esta lección debe ser aprendida, y comprendida en sus causas para revertirlo en el futuro.

\section{Intensidad de las políticas de contención y variables relevantes}

Es importante notar la naturaleza dinámica del fenómeno y de las respuestas de política. Las restricciones sobre actividades y las medidas de distanciamiento social son todavía de los pocos instrumentos que han probado contener dinámicas exponenciales en las variables sanitarias relacionadas a la pandemia. Necesariamente, estas medidas tienen un importante impacto socioeconómico.

Eichenbaum y otros (2020) y Guerreri y otros (2020), por ejemplo, proponen modelos para evaluar las interacciones. En la Fig. $N^{\circ} 1$ se presenta una simulación ilustrativa de las interacciones entre la población infectada (dentro de las variables epidemiológicas) en base a modelos específicos tradicionales en salud (SIR), modelos de comportamiento, e intervenciones de política pública medidas como restricciones a las interacciones (consumo e ingresos), así como los efectos en la pérdida de bienestar medido por el impacto económico medio—sin heterogeneidad entre agentes. En las figuras, la línea sólida muestra la evolución de variables en función del modelo macro SIR y de conducta individual de los agentes, sin intervención con medidas de distanciamiento. En negro-segmentado, las correcciones de curvas en presencia de restricciones sobre las actividades económicas.

\footnotetext{
"Visión de Futuro" Año 18, Volumen No 25 N 2, Edición Especial-III Congreso Regional de Economía del Norte Grande-Pág 31-55 URL de la Revista: http://visiondefuturo.fce.unam.edu.ar/index.php/visiondefuturo/index

URL del Documento: https://visiondefuturo.fce.unam.edu.ar/index.php/visiondefuturo/issue/view/20

ISSN 1668 - 8708 - Versión en Línea

E-mail: revistacientifica@fce.unam.edu.ar
} 
a) Población infectada con y sin medidas de distanciamiento

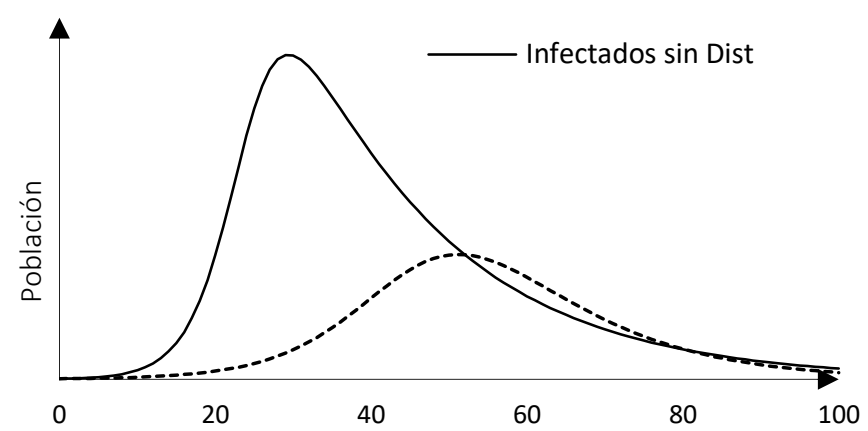

b) Pérdidas económicas con y sin medidas de distanciamiento

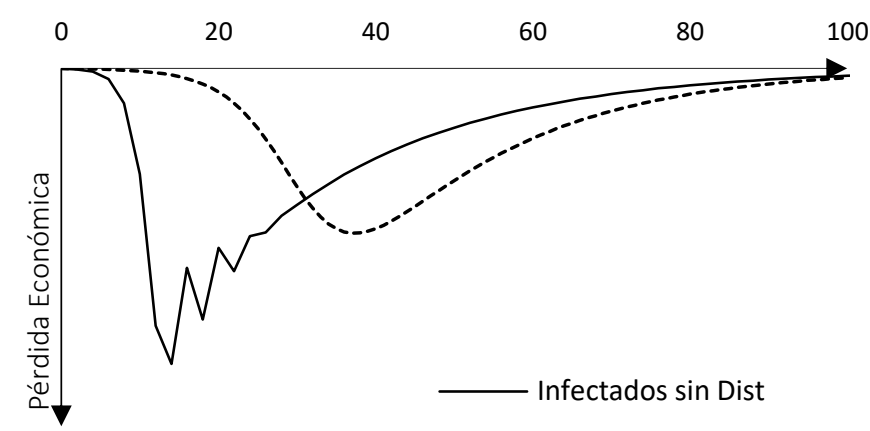

Figura $N^{\circ}$ 1. Modelo Macro-SIR con y sin políticas de distanciamiento

Fuente: Elaboración propia. Basado en Eichenbaum y otros (2020), y Guerreri y otros (2020)

Una observación sobre las figuras es que con intervención la cantidad de infectados y muertes puede ser significativamente menor. Si bien la profundidad de la recesión también es menor su duración es mucho más prolongada. Medida en semanas, más de 100. Una segunda y última explicación es que como los infectados son menores con intervención, la población de Susceptibles (potenciales infectados si expuestos al virus), es mucho mayor. Esto implica que relajar las restricciones puede disparar el comportamiento exponencial de infectados y sus implicancias.

\section{Heterogeneidad, segmentaciones y ¿dominancia de políticas?}

En general, la optimización de políticas importa criterios valorativos acerca de objetivos y horizontes temporales que presentan grados variables de tensión. Desde la economía del bienestar, la discusión pasa por los criterios valorativos que determinan ponderaciones normativas; desde la economía política, la valoración es de hecho, lo que se observa gobernado por reglas de juego, incentivos y actores.

Acemoglu y otros (2020) discuten que los casos extremos, no intervención e intervención con medidas homogéneas, son dominados por políticas segmentadas en el caso

\footnotetext{
"Visión de Futuro" Año 18, Volumen No 25 No 2, Edición Especial-III Congreso Regional de Economía del Norte Grande-Pág 31-55 URL de la Revista: http://visiondefuturo.fce.unam.edu.ar/index.php/visiondefuturo/index

URL del Documento: https://visiondefuturo.fce.unam.edu.ar/index.php/visiondefuturo/issue/view/20

ISSN 1668 - 8708 - Versión en Línea

E-mail: revistacientifica@fce.unam.edu.ar
} 
de que existan heterogeneidades relevantes. Su trabajo se enfoca en la heterogeneidad en las tasas epidemiológicas, por edades.

Uno de los problemas entonces es determinar las fuentes de heterogeneidad relevantes que puedan ser explotadas con políticas segmentadas. Este punto es más demandante de lo que parece a simple vista. La incertidumbre asociada tanto a las distinciones como a los parámetros asociados es clave no sólo desde un punto de vista de la viabilidad y oportunidad técnica, pero también política.

Parte del trabajo se refiere a detectar o convalidar las fuentes de heterogeneidad relevantes y reducir la incertidumbre asociada a parametrizaciones en distintos niveles de segmentación, dentro de dos grandes grupos:

- Asociadas a componentes epidemiológicos. Incluye las segmentaciones por edad, naturaleza epidemiológica (tipo de circulación), culturales, entre otras.

- Socioeconómicas. Incluye características de las actividades, del trabajo, de la sociabilidad asociada, de la naturaleza contractual subyacente, vulnerabilidad (social, financiera), entre otros.

\section{Medidas paliativas y de la recuperación post-pandemia}

Las segmentaciones incluyen criterios de vulnerabilidad tanto desde el punto de vista epidemiológicos como socioeconómicos y productivos durante la pandemia. Pero los impactos agregados deben incluir evaluaciones acerca de los impactos socioeconómicos, distributivos de acuerdo con su nivel de persistencia. Los cierres de empresa y la destrucción de capitales específicos asociados (know-how, emprendedor, etc.), el deterioro social con los efectos sobre el capital humano y la dinámica social, son algunos de los aspectos a considerar desde el punto de vista de las políticas.

La capacidad de recuperación a una nueva normalidad estará condicionada por la naturaleza de los shocks y de su persistencia.

\section{Dinámicas epidemiológicas y económicas}

El primer caso de infección por Coronavirus (SARS-CoV-2 o Covid-19), confirmado dentro de Argentina, se produjo el 03 de marzo de 2019 en la Ciudad Autónoma de Buenos Aires (CABA). Desde entonces, los contagios afectaron a la totalidad de las provincias argentinas, arribando en momentos diferentes y mostrando dinámicas diversas.

\section{Heterogeneidades espaciales en las dinámicas epidemiológicas}

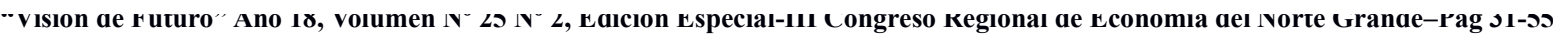
URL de la Revista: http://visiondefuturo.fce.unam.edu.ar/index.php/visiondefuturo/index

URL del Documento: https://visiondefuturo.fce.unam.edu.ar/index.php/visiondefuturo/issue/view/20 
Luego de 120 días desde el primer caso confirmado en CABA, los diez distritos más afectados en términos de cantidad de casos son Provincia de Buenos Aires (con 47.789 casos), CABA (35.467), Chaco (2446), Río Negro (1.031), Córdoba (826), Neuquén (649), Santa Fé (480), Entre Ríos (376), Jujuy (315) y Mendoza (255). Sin embargo, estos distritos han mostrado diferentes dinámicas de contagios y fallecimientos, lo cual debe ser analizado al resultar un factor relevante en el diseño de políticas públicas para la mitigación de la epidemia.

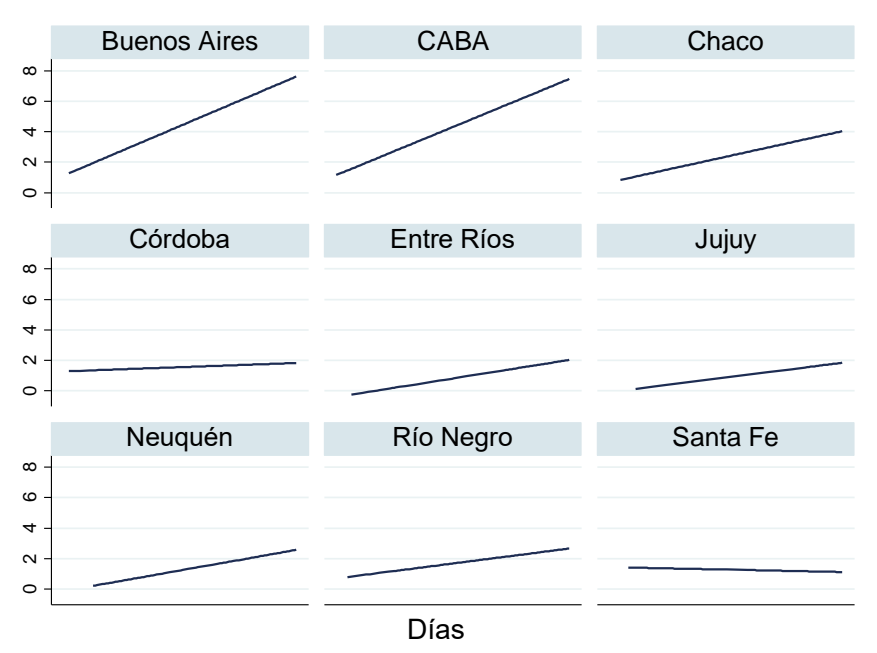

Figura $N^{\circ}$ 2: Tendencia de casos confirmados diarios (escala logarítmica), en distritos más afectados

Fuente: Elaboración propia en base a datos públicos del Ministerio de Salud de la Nación.

Un primer aspecto a considerar es la heterogeneidad en las trayectorias temporales de las infecciones diarias, o incidencia diaria en términos epidemiológicos. La Fig. № 2 ilustra la heterogeneidad de trayectorias temporales dentro de los diez distritos más afectados, usando como variable la cantidad de infectados diarios en escala logarítmica, siendo CABA la que lidera en tendencia positiva, seguida de Provincia de Buenos Aires, Chaco y Entre Ríos. En el otro extremo está Santa Fé, distrito que tuvo gran cantidad de casos en el inicio de la epidemia, pero fue controlando el ritmo de contagios hasta lograr una reversión de la tendencia global.

La región del Norte Grande Argentino, definida como la suma de las regiones Nordeste y Noroeste (NEA y NOA), también presenta una heterogeneidad muy marcada entre distritos provinciales, en cuanto a dinámica de infectados por día (Fig. $N^{\circ} 3$ ). Este caso regional es ejemplo de una situación importante a considerar, como el hecho de existir distritos sin casos (o muy pocos) por un período de tiempo inicial y luego tales distritos presentar casos de contagios en escala significativa más adelante en el tiempo, como las provincias de Formosa,

Catamarca y Jujuy.

\footnotetext{
"Visión de Futuro" Año 18, Volumen No 25 N 2, Edición Especial-III Congreso Regional de Economía del Norte Grande-Pág 31-55 URL de la Revista: http://visiondefuturo.fce.unam.edu.ar/index.php/visiondefuturo/index

URL del Documento: https://visiondefuturo.fce.unam.edu.ar/index.php/visiondefuturo/issue/view/20

ISSN 1668 - 8708 - Versión en Línea

E-mail: revistacientifica@fce.unam.edu.ar
} 


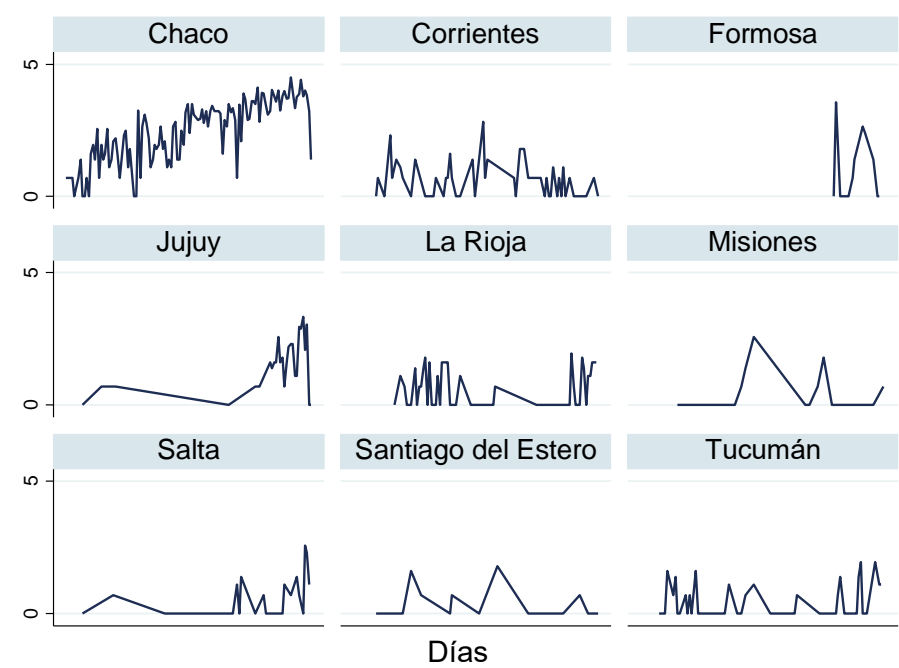

Figura $N^{\circ}$ 3: Número de casos diarios (escala logarítmica), Región Norte (NEA-NOA excepto Catamarca)

Fuente: Elaboración propia en base a datos públicos del Ministerio de Salud de la Nación.

Esta situación es relevante al indicar que no es posible dar por "segura" una zona geográfica sin casos mientras otras zonas estén siendo afectadas. Esto obliga a no descuidar las políticas y protocolos anti-contagios en zonas libres de virus hasta tanto todas las regiones del país (e incluso del exterior con mayor intercambio) estén libres también.

Dentro de la región Norte Grande, la provincia del Chaco presenta la situación más delicada con alta circulación comunitaria. Sin embargo, dentro del territorio chaqueño coexisten zonas con alto contagio con otras en las que no se diagnosticaron casos. En primer lugar, se puede diferenciar entre la zona del Área Metropolitana del Gran Resistencia (AMGR) y el resto de la provincia (que llamaremos el Interior).

Por un lado, el AMGR presentó la tendencia de contagios predominante desde el inicio de la epidemia nacional mientras, por el otro lado, el Interior mostró pocos casos con períodos de tiempo sin casos (Fig. $N^{\circ} 4$ ). Sin embargo, pasados los 90 días de epidemia, el Interior inicia una senda de contagios diarios abrupta, pasando de un promedio de 1,3 casos diarios a uno de 10 de casos por día.

\footnotetext{
"Visión de Futuro" Año 18, Volumen No 25 No 2, Edición Especial-III Congreso Regional de Economía del Norte Grande-Pág 31-55 URL de la Revista: http://visiondefuturo.fce.unam.edu.ar/index.php/visiondefuturo/index

URL del Documento: https://visiondefuturo.fce.unam.edu.ar/index.php/visiondefuturo/issue/view/20

ISSN 1668 - 8708 - Versión en Línea

E-mail: revistacientifica@fce.unam.edu.ar
} 
Área Metropolitana del Gran Resistencia

Interior del Chaco
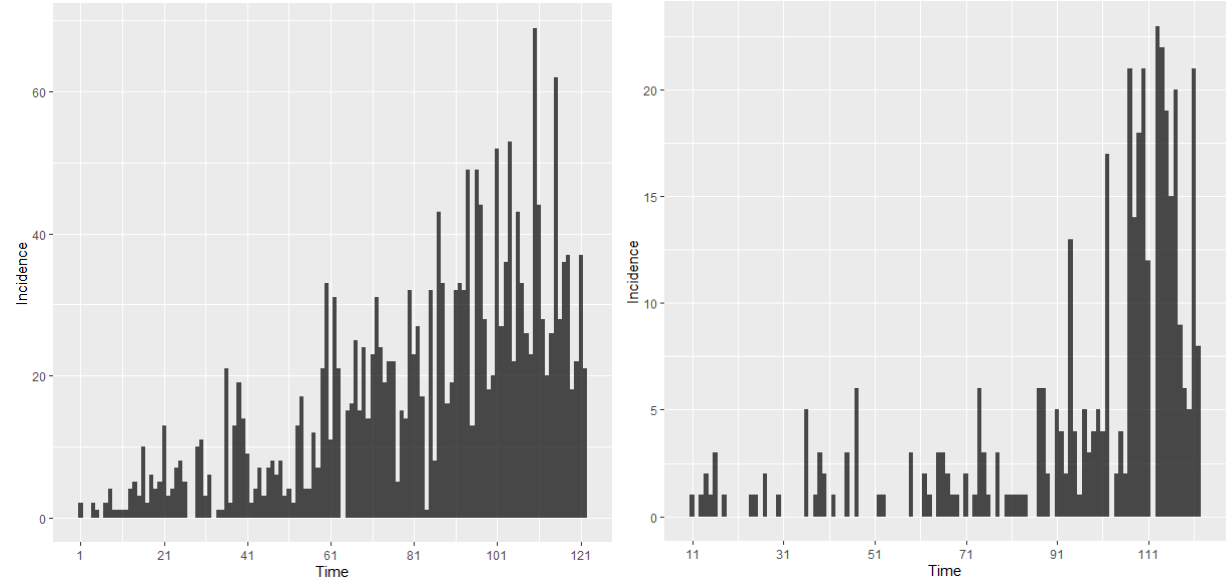

Figura $N^{\circ}$ 4: Número de casos de infectados diarios, AMGR e Interior.

Fuente: Elaboración propia en base a datos suministrados por el Ministerio de Salud de la Provincia del Chaco.

Barrio Gran Toba Resistencia

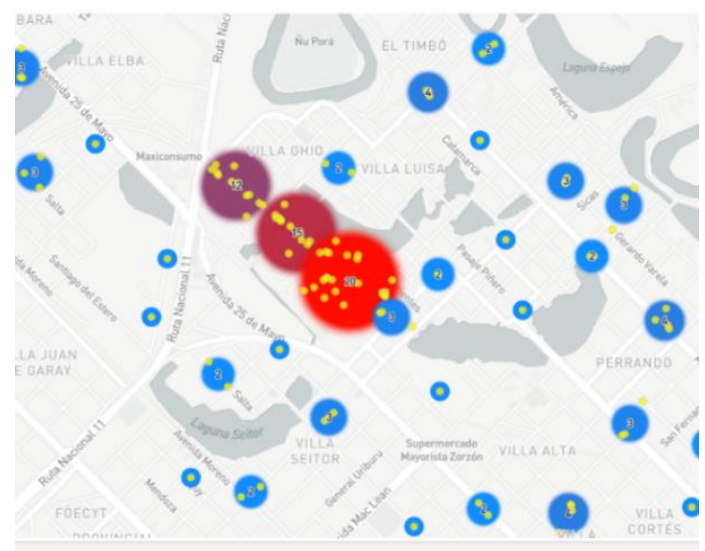

Mapic; Don Santiago y Chacra (Resistencia)
Cacique Pelayo (fontana)

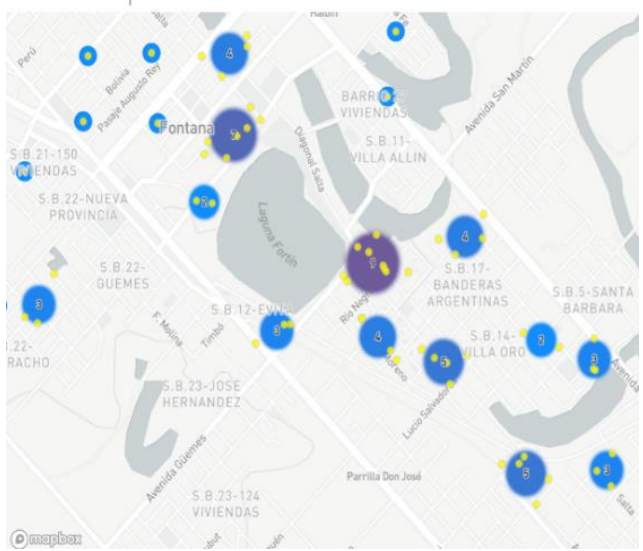

Barrio Belgrano (Resistencia)

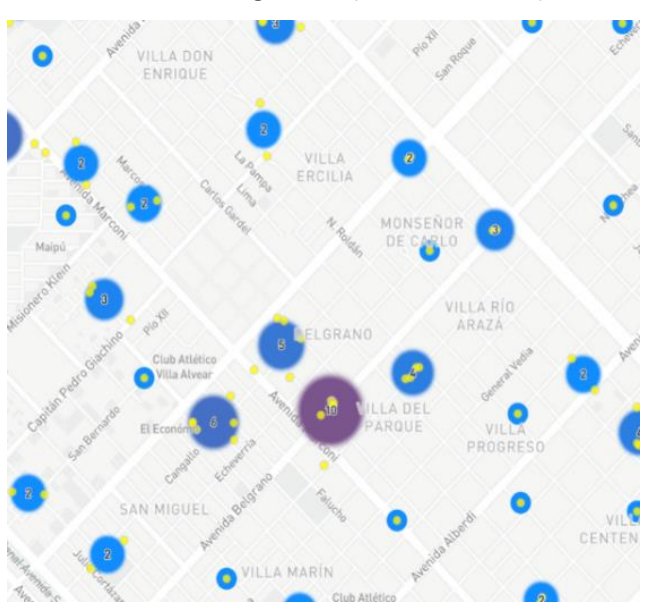

Figura $\mathbf{N}^{\circ}$ 5. Número de casos positivos activos coexistentes espacialmente, AMGR e Interior.

Fuente: Elaboración propia en base a datos suministrados por el Gobierno de la Provincia del Chaco.

\footnotetext{
"Visión de Futuro" Año 18, Volumen No 25 N² 2, Edición Especial-III Congreso Regional de Economía del Norte Grande-Pág 31-55 URL de la Revista: http://visiondefuturo.fce.unam.edu.ar/index.php/visiondefuturo/index

URL del Documento: https://visiondefuturo.fce.unam.edu.ar/index.php/visiondefuturo/issue/view/20

ISSN 1668 - 8708 - Versión en Línea

E-mail: revistacientifica@fce.unam.edu.ar
} 
Finalmente, incluso dentro del AMGR, existió una marcada heterogeneidad espacial en cuanto a zonas afectadas, donde el fenómeno epidemiológico estuvo definido por la existencia de "focos" de contagios (Figura 5). En AMGR se desarrollaron focos específicos, como el del Barrio Gran Toba con 167 casos, el de la zona de Barrios Mapic, Don Santiago y Chacra, superando los 20 casos. Y el de la ciudad de Fontana en el Barrio Cacique Pelayo, con 30 casos.

\section{Heterogeneidades espaciales en movilidad}

Otra dimensión que posee una dinámica geográficamente heterogénea es la movilidad de las personas, en particular dentro de un contexto de medidas de aislamiento social como el ASPO (Aislamiento Social Preventivo Obligatorio) implementado en argentina desde el 19 de marzo del 2020.

Un primer aspecto a considerar es cuánto puede reducirse la movilidad de las personas bajo ASPO, tanto en términos generales como en actividades específicas y cómo dicha reducción puede variar geográficamente. Una hipótesis inicial es que tal reducción dependerá de factores socioeconómicos, como por ejemplo la oportunidad de migrar al teletrabajo (homeoffice), el nivel de ingreso y ahorro familiar, el grado de formalidad del mercado laboral privado, etc.

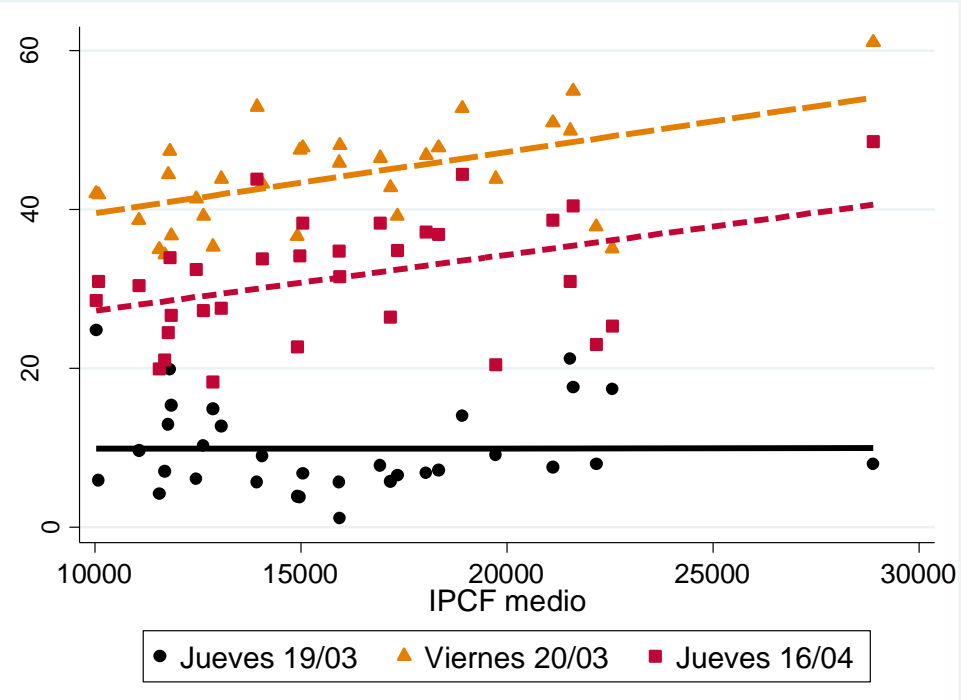

Figura $N^{\circ}$ 6: Reducción de la Movilidad General (\%): 32 aglomerados principales del país.

Fuente: Elaboración propia en base a datos de movilidad de Grandata.

La Fig. N6 insinúa que existe una relación positiva entre la reducción de la movilidad general y el Ingreso Per-cápita Familiar (IPCF), además de mostrar que la movilidad general se redujo en torno al $20 \%$ y el $35 \%$ en términos medios, si se compara el día previo a entrar en cuarentena (19/03) versus el día posterior y el mismo día de la semana al cabo de cuatro

\footnotetext{
"Visión de Futuro" Año 18, Volumen No 25 º 2, Edición Especial-III Congreso Regional de Economía del Norte Grande-Pág 31-55 URL de la Revista: http://visiondefuturo.fce.unam.edu.ar/index.php/visiondefuturo/index

URL del Documento: https://visiondefuturo.fce.unam.edu.ar/index.php/visiondefuturo/issue/view/20

ISSN 1668 - 8708 - Versión en Línea

E-mail: revistacientifica@fce.unam.edu.ar
} 
semanas (16/04). Esta heterogeneidad en la reducción de la movilidad es esperada a priori, ya que los aglomerados con menos IPCF suelen ser aquellos con menor ahorro familiar, más informalidad laboral y menor posibilidad de implementar el teletrabajo. En la Fig. $N^{\circ} 6$ de aprecia también una caída en la reducción de movilidad al transcurrir un mes de ASPO (medición del 16 de abril), lo cual es lógico en un contexto donde muchos distritos no poseían aún altas tasas de contagio por lo que fueron flexibilizando el aislamiento o incumpliéndolo.

Para analizar el aumento de la movilidad durante la vigencia del ASPO, en igualdad de condiciones epidemiológicas, el la Fig. 7 presenta las dinámicas temporales de movilidad laboral para los tres distritos más afectados durante todo el período de análisis. Un primer punto a notar es que Chaco reduce menos su movilidad laboral al inicio del ASPO, seguido de Provincia de Buenos Aires (PBA) y de CABA. Tal hecho es consistente con lo mencionado previamente sobre factores asociados al IPCF y su efecto sobre la movilidad. Un segundo punto es la velocidad de recuperación de la movilidad al transcurrir el tiempo, donde se aprecia a Chaco con una tasa mayor de recuperación, seguido de PBA y luego CABA con la menor recuperación. Esto también abona la idea de heterogeneidades explicadas por diferentes situaciones económicas, perfiles laborales y economía formal.

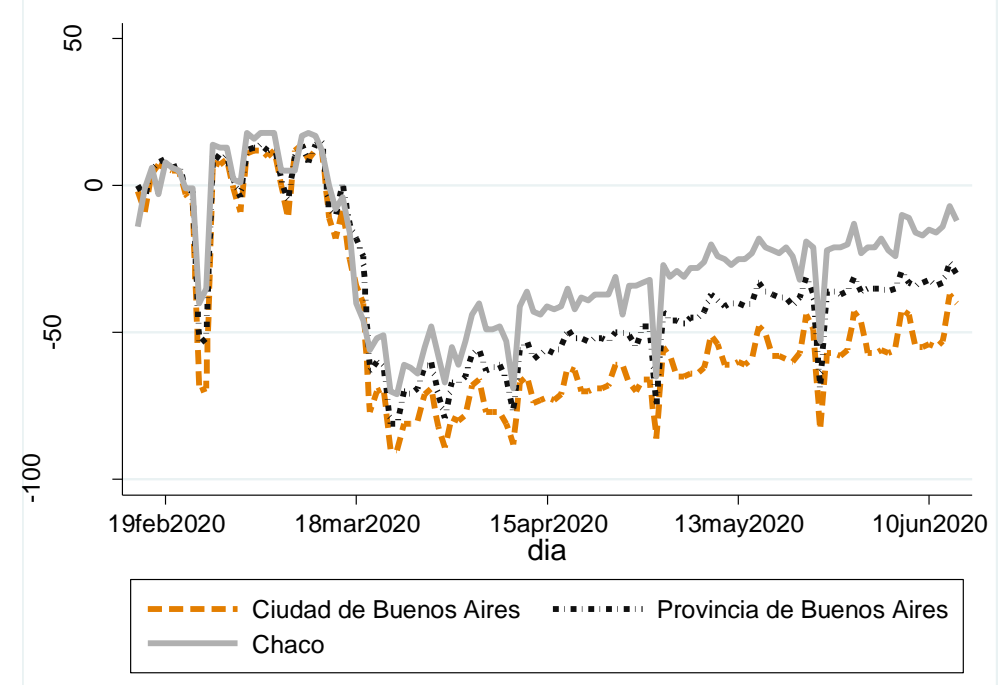

Figura N 7: Reducción de la Movilidad Laboral (\% negativo): Chaco, Prov. de Bs. As. y CABA.

Fuente: Elaboración propia en base a datos de movilidad de Google Mobility.

Como es de esperar, esta heterogeneidad en la respuesta al ASPO también puede estar presente a nivel de aglomerados, como la Ciudad de Resistencia en Chaco, CABA y diferentes municipios de PBA. Ilustrando el caso de la región Norte, La Fig. 8 presenta un mapa que grafica la distribución espacial del nivel de movilidad. Se puede apreciar en el mapa cómo la región sur de la cuidad refleja una movilidad Muy Alta durante ASPO (superior al 90\% respecto a la movilidad base del 100\% medida sin ASPO). Paralelamente, la región del Macrocentro

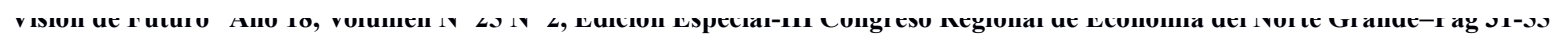
URL de la Revista: http://visiondefuturo.fce.unam.edu.ar/index.php/visiondefuturo/index URL del Documento: https://visiondefuturo.fce.unam.edu.ar/index.php/visiondefuturo/issue/view/20 
de la cuidad presenta movilidad Alta mientras que el Microcentro muestra un nivel de Madia y Baja movilidad.

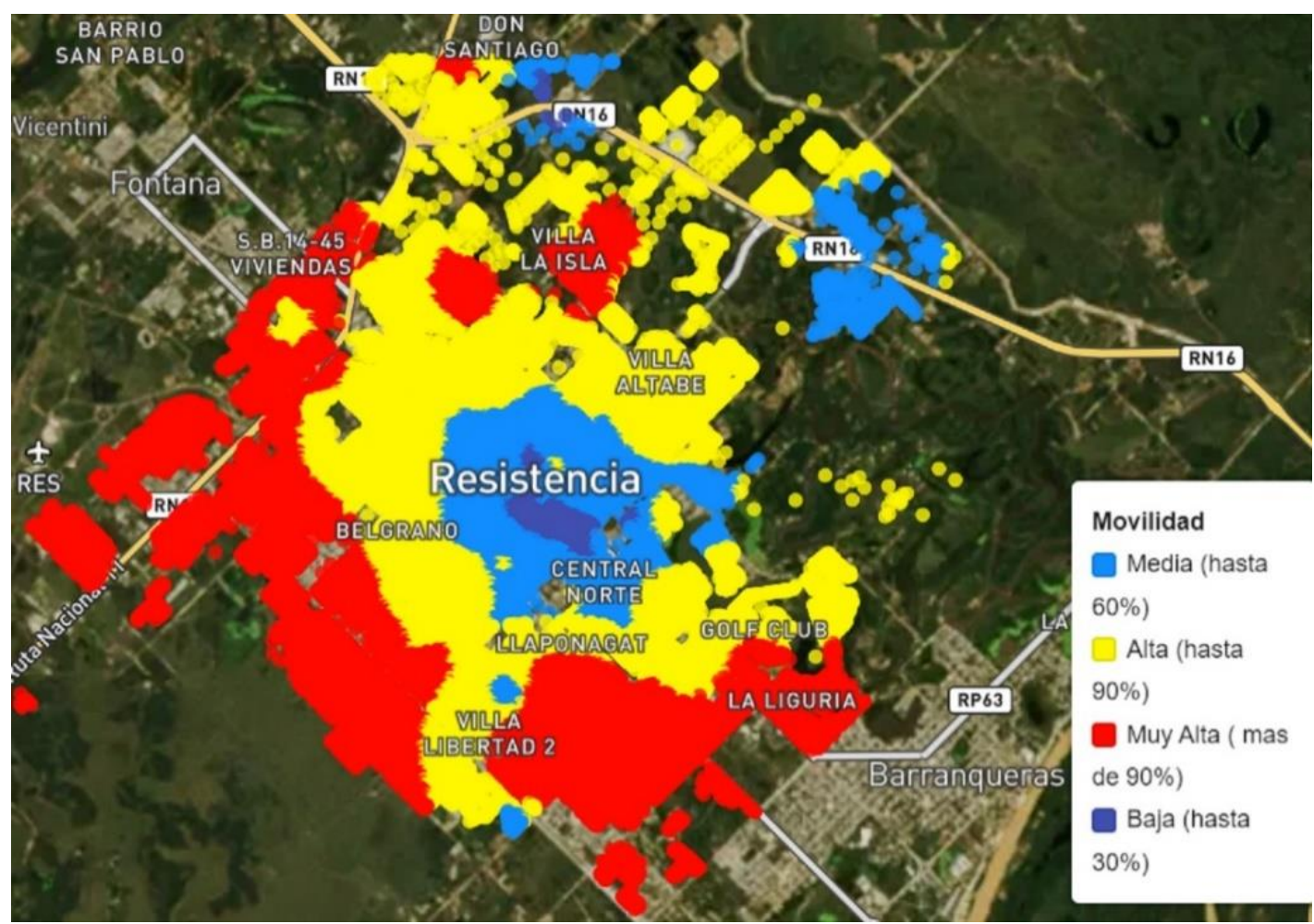

Figura 8: Heterogeneidad de Movilidad: Zonas del Gran Resistencia.

Fuente: Elaboración propia en base a datos de movilidad de Telefonía Celular.

\section{Heterogeneidad en riesgo de muerte por Covid-19}

Otra fuente de heterogeneidad relevante para el diseño de políticas, tanto de aislamiento como sanitarias, es el impacto de los contagios sobre la mortalidad. Sobre esta fuente actúan factores demográficos como la estructura etaria de la población, conductuales como el cumplimiento del ASPO y otros factores socioeconómicos y de infraestructura.

Uno de los principales factores de riesgo es la edad del paciente, dada su asociación con el estado inmunológico general y con otros factores de riesgo dados por comorbilidades (Li y otros, 2020 y Jordan y otros 2020). Al observar cómo se distribuyen los casos de fallecimientos por años de edad y distrito (Fig. №9), se aprecia una mayor afección en edades tempranas (entre 25 y 65 años) dentro de la Provincia del Chaco, comparada contra CABA y PBA.

\footnotetext{
"Visión de Futuro" Año 18, Volumen No 25 No 2, Edición Especial-III Congreso Regional de Economía del Norte Grande-Pág 31-55 URL de la Revista: http://visiondefuturo.fce.unam.edu.ar/index.php/visiondefuturo/index

URL del Documento: https://visiondefuturo.fce.unam.edu.ar/index.php/visiondefuturo/issue/view/20

ISSN 1668 - 8708 - Versión en Línea

E-mail: revistacientifica@fce.unam.edu.ar
} 


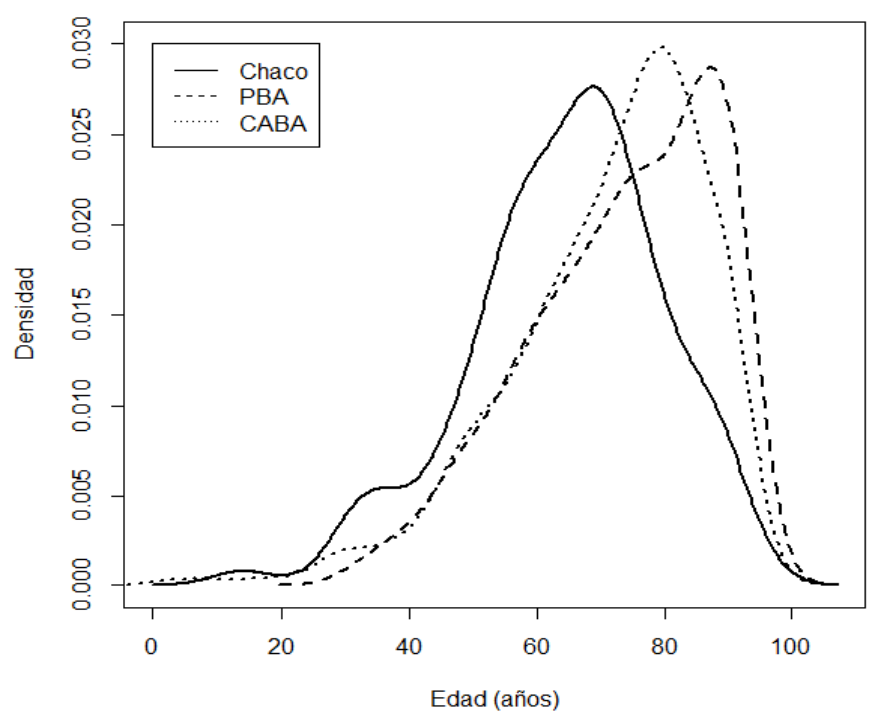

Figura $N^{\circ}$ 9: Heterogeneidad en Mortalidad por edades y distritos.

Fuente: Elaboración propia en base a datos públicos del Ministerio de Salud de la Nación.

Otra combinación de factores relevante es Edad con Sexo, la cual tiene un efecto explicativo significativo sobre el riesgo de muerte, además de presentar diferencias sustanciales entre hombres y mujeres. El efecto heterogéneo de esta combinación se evidencia en el Fig. $N^{\circ} 10$, donde el grupo de mujeres es el menos afectado condicionando por edad y distrito.
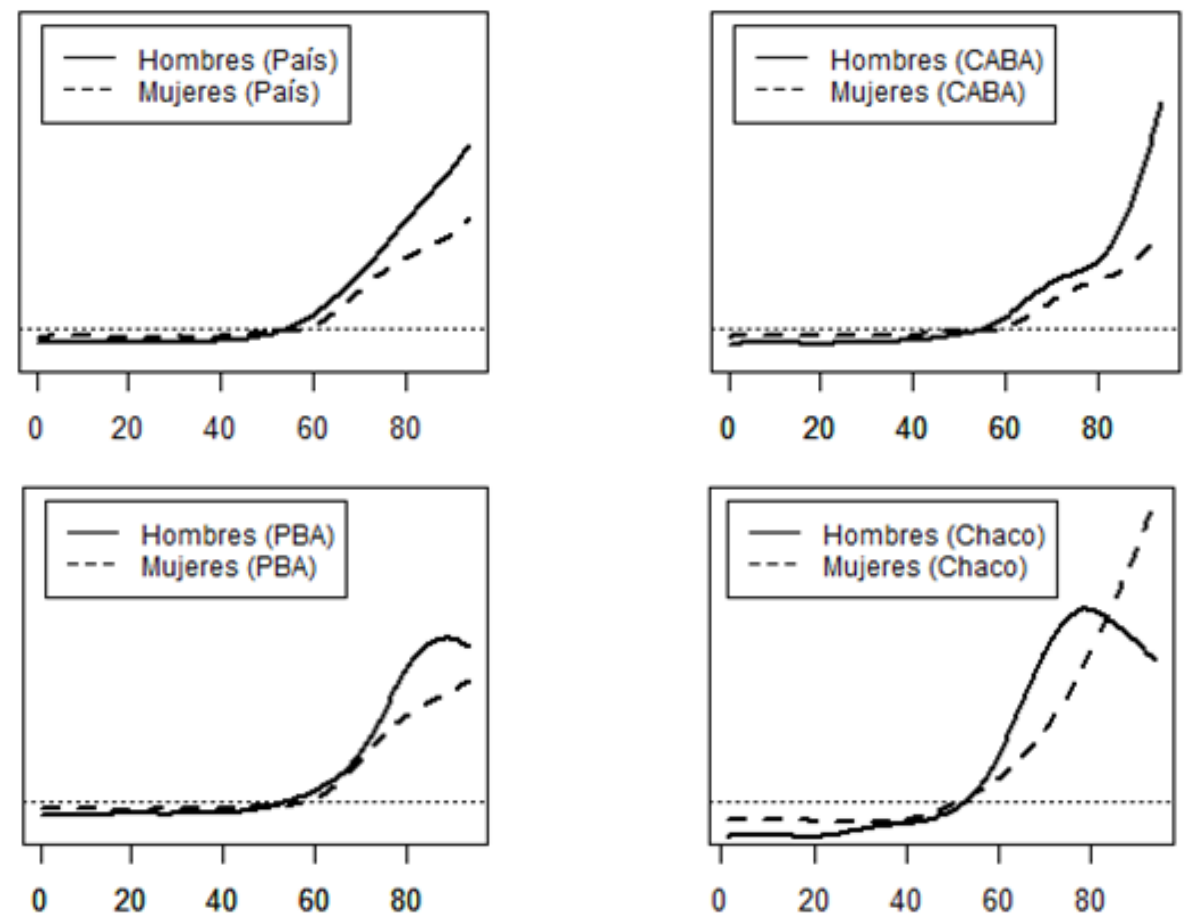

Figura $\mathrm{N}^{\circ}$ 10: Heterogeneidad en Riesgo de muerte por Edad, Sexo y distrito.

Fuente: Elaboración propia en base a datos públicos del Ministerio de Salud de la Nación.

\footnotetext{
"Visión de Futuro" Año 18, Volumen No 25 No 2, Edición Especial-III Congreso Regional de Economía del Norte Grande-Pág 31-55 URL de la Revista: http://visiondefuturo.fce.unam.edu.ar/index.php/visiondefuturo/index

URL del Documento: https://visiondefuturo.fce.unam.edu.ar/index.php/visiondefuturo/issue/view/20

ISSN 1668 - 8708 - Versión en Línea

E-mail: revistacientifica@fce.unam.edu.ar
} 
En el caso de Chaco se aprecia cómo el riesgo de muerte comienza a elevarse suavemente a partir de los 20 años de edad para Hombres, mientras que en PBA y CABA comienza a crecer desde los 40-45 años de edad. Para el grupo de pacientes Mujeres, el riesgo medio comienza a elevarse desde los 40 años en Chaco, mientras que en CABA y PBA lo hace desde los 55 años de edad, aproximadamente.

Las diferencias geográficas ilustradas en estos ejemplos se pueden extender a todas las provincias argentinas y hacia dentro de las mismas. Esta heterogeneidad espacial debe su existencia a factores demográficos y socioeconómicos diversos que afectan conductas y estados de salud previos, los que están siendo analizados como en Sannigrahi y otros (2020) y Sun, Hu \& Xie (2020).

\section{Impacto económico y políticas públicas}

Inicialmente las normas de distanciamiento fueron absolutamente centralizadas, y aplicación formal uniforme. En el territorio, la aplicación de hecho ha sido dispar desde el inicio, condicionada en parte por heterogeneidades epidemiológicas como las ilustradas en la sección previa. Según las condiciones epidemiológicas y de capacidades locales, las dinámicas han resultado específicas, aunque con componentes sistémicos propios de un shock de magnitud agregado. En nuestra región, el peso, situación y orientación del Sector público son factores relevantes. Esto afecta la estructura y composición de la actividad, del empleo y de los mercados de crédito, afectando segmentaciones y vulnerabilidades relativas.

El Sector Público recibe la desaceleración de recursos de coparticipación que, por peso, es el principal canal de transmisión externo a través de las posibilidades de afrontar sus obligaciones reales (salariales, etc.) con condiciones iniciales de estrés fiscal, y con necesidades de adicionales para atender las demandas del sistema de salud, educativo y de seguridad social.

Los sectores privados en cierre (excluidos del listado de actividades permitidas o con limitaciones más adelante) se ven afectados directamente en sus ingresos. En principio consiste en un shock "transitorio" de oferta, dado que no hay empleo para la producción o prestación, y sufrirán una caída (casi) total de ingresos. La oferta se cierra en estos sectores.

En términos generales, la pérdida de ventas e ingresos choca con las estructuras y tamaños de los costos. Uno de ellos es el laboral, que retroalimenta en caídas de demanda y en la vulnerabilidad agregada social y económica. Algunos sectores podrán pagar con grados variables las nóminas salariales y/o renegociar compromisos asociados en manera parcial o total. Las alternativas para afrontar este flujo de costos sin considerar la estructura de financiamiento del capital, en principio, son todas posibles en el contexto de la emergencia,

\footnotetext{
"Visión de Futuro" Año 18, Volumen N²5 N², Edición Especial-III Congreso Regional de Economía del Norte Grande-Pág 31-55 URL de la Revista: http://visiondefuturo.fce.unam.edu.ar/index.php/visiondefuturo/index

URL del Documento: https://visiondefuturo.fce.unam.edu.ar/index.php/visiondefuturo/issue/view/20

ISSN 1668 - 8708 - Versión en Línea

E-mail: revistacientifica@fce.unam.edu.ar
} 
pero su oportunidad y efectos dinámicos no son equivalentes. Incluyen desde suavizamiento vía subsidio y diferimientos impositivos, distribución del shock con renegociaciones y suspensiones contractuales, suavizamiento vía crédito, caída y liquidación de activos corrientes (si los tiene), cierre transitorio con/sin subsidio-crédito de subsistencia, y cierre indefinido. Otro canal de costos adicional vendrá de la mano de reducciones de ingresos reales y de reducciones en los patrones de consumo debido a la retracción de los agentes, sea por la incertidumbre sobre el futuro como por la aversión a la interacción social y exposición al contagio.

La persistencia del shock implicará que los déficits operativos de las empresas deberán cubrirse por acumulación de pasivos (des-acumulación de activos), o mediante la suspensión y/o renegociación contractual. En cualquier caso, la sustentabilidad de las empresas estará en riesgo variable en función de los sectores de actividad, componentes sistémicos e idiosincráticos a cada empresa (tamaño, estructura de costos, nivel y costo de endeudamiento).

Un objetivo de la agenda es evaluar dos ejes conceptuales relativos a la vulnerabilidad de segmentos de empresas, su capacidad de sobrevivencia durante la crisis epidemiológicasocioeconómica, y de recuperación post-crisis.

\section{Actividades y ocupaciones en el contexto del cierre. Posibilidades de segmentación}

Dentro de la literatura en proceso, las clasificaciones de actividades presentan distintos criterios en función de su exposición a características del ambiente epidemiológico-económico y de políticas. Las clasificaciones van desde su naturaleza económica hasta desde restricciones de política o legales impuestas. Otro a las oportunidades de reorganización tecnológica y/o espacial de la actividad para reducir la incidencia epidemiológica y económica del shock.

Existen varios criterios de clasificación de actividades, siendo una de ellas la adoptada por las normativas nacionales a lo largo del período de distanciamiento. Este es el criterio regulatorio para definir las actividades llamadas esenciales (Malani y otros, 2020). Otro criterio de clasificación de actividades es el adoptado por Alvarez y otros (2020), quienes realizan una clasificación entre regulares e intensivos, de acuerdo con el nivel de interacción social requerida por la actividad. La clasificación es nuevamente binaria, y supone que se pueden dividir actividades según la intensidad de contactos para clasificarlas en segmentos y tratamientos diferenciados en cuanto a niveles de restricción. Esta clasificación está estrechamente relacionada con las clasificaciones de otras investigaciones recientes

\footnotetext{
“Visión de Futuro" Año 18, Volumen N²5 N², Edición Especial-III Congreso Regional de Economía del Norte Grande-Pág 31-55 URL de la Revista: http://visiondefuturo.fce.unam.edu.ar/index.php/visiondefuturo/index

URL del Documento: https://visiondefuturo.fce.unam.edu.ar/index.php/visiondefuturo/issue/view/20

ISSN 1668 - 8708 - Versión en Línea

E-mail: revistacientifica@fce.unam.edu.ar
} 
centradas en la naturaleza del trabajo subyacente (Bonavida y Gasparini, 2020; Montenovo y otros 2020).

Otras fuentes de heterogeneidad están asociadas a la tecnología del trabajo. Un criterio general que presenta particiones interesantes es si el trabajo se realiza o podría realizarse en ausencia de interacciones sociales, o con mínimas interacciones interpersonales (Bonavida y Gasparini, 2020). Otros se refieren a la medida en que la protocolización de actividades referidas al número de interacciones en el trabajo (y el trayecto hacia, si lo hubiera) y a las tareas en si misma que presenten posibilidades significativas de reducciones de riesgo de exposición al contagio (Ferguson y otros, 2020). El caso más claro se refiere a los trabajos que permiten realizarse en ausencia de interacciones interpersonales, por ejemplo.

Los criterios que son susceptibles de evaluarse a partir de desarrollos de $\mathrm{ONE}^{\star} T$ (producto de datos patrocinado por el Departamento de Trabajo de EE.UU. utilizado para evaluar las características relacionadas con el trabajo de cada ocupación) y de evaluaciones nacionales acerca de la tecnología del trabajo, son:

Flexibilidad de la relación laboral. Básicamente se refiere a la posibilidad de teletrabajo y espacio laboral independiente. Uno de ellos es el trabajo desde la casa.

Sociabilidad del marco de interacción. Se refiere a la densidad de interacciones con clientes, proveedores, y pares.

Cada uno de estos grandes criterios deben especificarse y recategorizarse por casos. Incluso dinámicamente, dado que los tipos de trabajo pueden eventualmente reconvertirse.

A nivel práctico, para Argentina, la variable que permite caracterizar la actividad ocupacional de las personas, sigue el Clasificador Nacional de Ocupaciones (CON) de la Encuesta Permanente de Hogares, (EPH, del INDEC), el cual consiste en un código, que tiene en cuenta la finalidad del trabajo (carácter), la complejidad de la tarea (calificación), el carácter general y el Carácter específico (Jerarquía y Tecnología). 


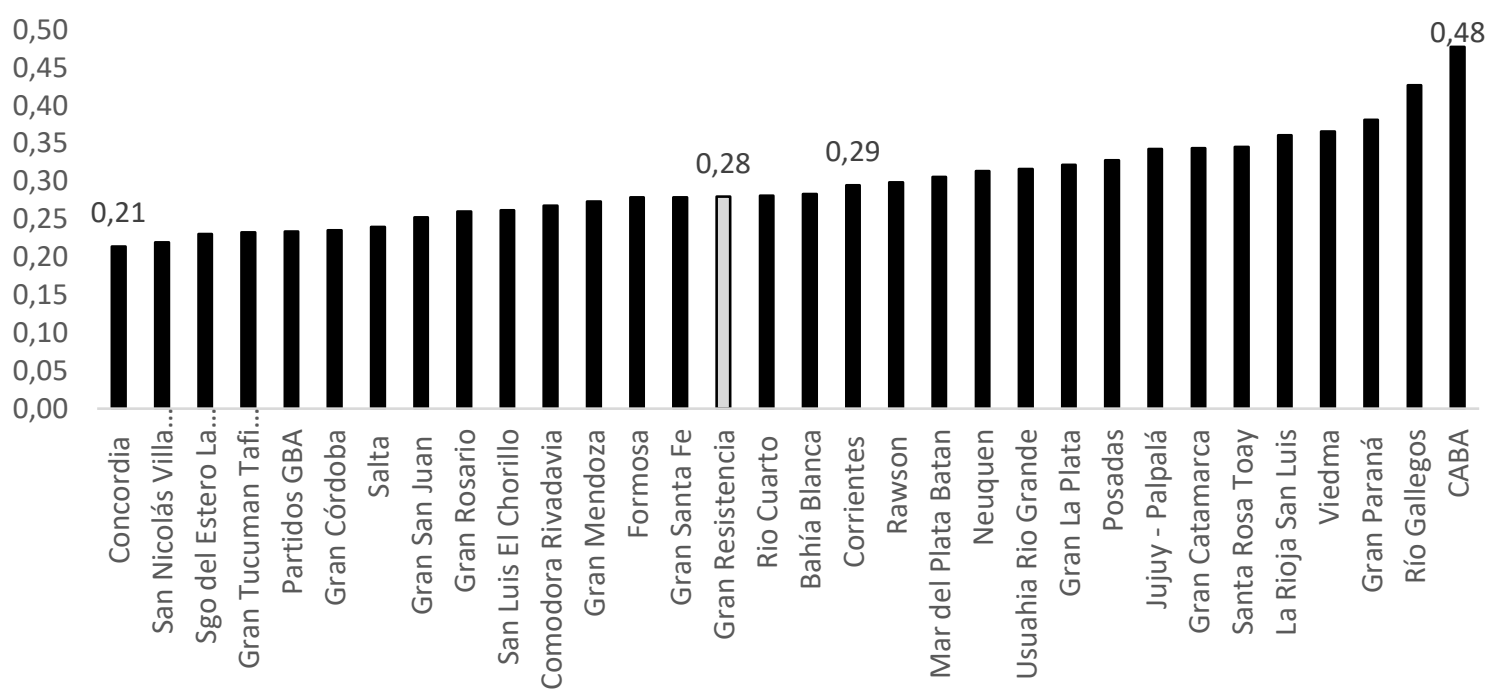

Figura $\mathrm{N}^{\circ}$ 11. Posibilidades de teletrabajo por aglomerado (en \%)

Fuente: Elaboración propia en base a EPH, Albanesi y otros (2020), ONET y Albrieu (2020).

En la Fig. №11 se presenta un resumen ilustrativo sobre cómo pueden agregarse los criterios mencionados en un simple indicador que sugiera la posibilidad de teletrabajo en la población laboral. A nivel estilizado sugiere que, en un marco relativamente optimista de reconversión, el porcentaje de trabajos que puede realizarse desde el hogar o en forma remota se encuentra en valores cercanos al $30 \%$ de los trabajos totales. Es un número muy relevante en términos del total de la fuerza laboral y las implicancias sobre la movilidad, productividad y eficiencia del sistema territorial urbano y agregado.

Nuevamente, el agregado encubre heterogeneidades relevantes. Aunque el caso del aglomerado del Gran Resistencia y de Corrientes, presentan valores cercanos al promedio, CABA se encuentra en el extremo de posibilidades de reconversión con casi un $50 \%$ de posibilidades de teletrabajo.

\section{Pandemia de covid-19 y economía del comportamiento}

Con el objeto se diseñar e implementar políticas en el contexto de la pandemia, se requiere una comprensión adecuada de la conducta de las personas y grupos dentro de la sociedad bajo las circunstancias novedosas. La economía del comportamiento utiliza ideas de los campos de la psicología, la neurociencia y ciencias cognitivas para explicar cómo se desvían los comportamientos de las personas de la teoría de la elección racional y cuándo y por qué las decisiones a corto plazo de las personas pueden socavar sus intereses de largo plazo. El objetivo de este campo es lograr una mejor predicción y comprensión de los comportamientos de las personas para ayudar a formular políticas públicas más efectivas.

\footnotetext{
"Visión de Futuro" Año 18, Volumen No 25 № 2, Edición Especial-III Congreso Regional de Economía del Norte Grande-Pág 31-55 URL de la Revista: http://visiondefuturo.fce.unam.edu.ar/index.php/visiondefuturo/index

URL del Documento: https://visiondefuturo.fce.unam.edu.ar/index.php/visiondefuturo/issue/view/20 
En esta sección, basada en Soofi et al. (2020) y en Martínez Villarreal et al. (2020), presentamos una serie de ideas de la economía del comportamiento que pueden ayudar a formular políticas públicas para mitigar la propagación de COVID-19 de manera más efectiva.

\section{Sesgo hacia el presente}

En el contexto de las elecciones intertemporales, los costos y beneficios de nuestras elecciones ocurren en diferentes momentos, es decir, muchas de las elecciones diarias resultan de una evaluación de resultados inmediatos y resultados futuros esperados. El sesgo hacia el presente es la tendencia no constante y no lineal de muchas personas a preferir una recompensa más pequeña pero más cercana al presente sobre un pago futuro más grande (Laibson, 1997; O'Donoghue \& Rabin, 1999; Loewenstein et al., 2012).

El sesgo puede conducir a preferencias inconsistentes en el tiempo. Un individuo hace un plan para mañana, pero una vez que llegue mañana puede experimentar una reversión de preferencias y revisar su plan. Se ha demostrado que el sesgo actual es un predictor significativo de una amplia variedad de comportamientos relacionados con la salud. Por ejemplo, fumar tiene tanto beneficios actuales (alivio temporal del estrés) como costos futuros (mayor riesgo de cáncer de pulmón). En el caso de COVID-19, no adherirse a políticas de quedarse en casa implican un trade-off entre el placer de ir al centro comercial o restaurante ahora (beneficio actual) y el aumento riesgo de contraer COVID-19 en el futuro (costo futuro incierto). El costo futuro incierto significa que no todas las excursiones fuera de la casa provocarán una infección por COVID-19. Así, es menos probable que individuos miopes (es decir, aquellos con sesgo hacia el presente), que ponen un mayor énfasis en el aquí y ahora, se adhieran a los comportamientos preventivos de COVID-19, incluyendo quedarse en casa y el lavado de manos. El sesgo hacia el presente es una explicación de por qué las personas no se comportan de acuerdo a su propio interés y por qué tienen dificultad para adherirse a comportamientos preventivos de salud como el distanciamiento social, incluso cuando desean hacerlo.

Aunque el sesgo hacia el presente puede conducir a un comportamiento subóptimo, se puede usar para ayudar a las personas a adherirse a conductas que prevengan o mitiguen la propagación del COVID-19, reduciendo los costos de la adhesión al distanciamiento social o aumentando sus beneficios. Algunas intervenciones que involucran recompensas de bajo costo se han utilizado como formas de aumentar los beneficios actuales de la adherencia a la medicación antirretroviral (Linnemayr, 2017), dejar de fumar (Halpern, 2015) y pérdida de peso (John, 2011), y se ha demostrado que son eficaces en cambiar comportamientos. Para reducir la transmisión del COVID-19, a corto plazo, proporcionar acceso gratuito a internet en el hogar

\footnotetext{
"Visión de Futuro" Año 18, Volumen N²5 N², Edición Especial-III Congreso Regional de Economía del Norte Grande-Pág 31-55 URL de la Revista: http://visiondefuturo.fce.unam.edu.ar/index.php/visiondefuturo/index

URL del Documento: https://visiondefuturo.fce.unam.edu.ar/index.php/visiondefuturo/issue/view/20

ISSN 1668 - 8708 - Versión en Línea

E-mail: revistacientifica@fce.unam.edu.ar
} 
o subsidiarlo, suspensión temporal de pagos de préstamos (por ejemplo, préstamos proporcionados por el gobierno para apoyar a desempleados), y proporcionar paquetes de beneficios para grupos vulnerables, deben ser considerados para alentar a las personas a adherirse a la política de quedarse en casa y para aumentar su probabilidad de éxito.

\section{El efecto de encuadre}

El efecto de encuadre se refiere al hecho de que las elecciones de los individuos a menudo dependen de la forma en que se describen o enmarcan las opciones, y que estas opciones a menudo se ven afectadas si los resultados se enmarcan en términos de ganancias o pérdidas (Tversky y Kahneman, 1979).

Este concepto está estrechamente asociado con la aversión a la pérdida, lo que implica que la desutilidad causada por una cantidad dada de pérdida es mayor, en valor absoluto, que la utilidad de obtener la misma cantidad. Por ejemplo, las declaraciones "las probabilidades de supervivencia después de una cirugía son $90 \%$ " y "las probabilidades de mortalidad dentro de 1 mes de cirugía son 10\%" provocan diferentes reacciones. Ambas declaraciones ofrecen la misma información, pero muchas personas reaccionan de manera diferente al riesgo de cirugía según cómo se presente (Luoto \& Carman, 2014).

Los estudios han demostrado que los mensajes enmarcados como ganancias son a menudo más efectivos para promover comportamientos preventivos. Un meta-análisis de 94 estudios encontró que los mensajes de salud enmarcados como ganancias fueron significativamente más propensos a aumentar la prevención que los enmarcados como pérdidas (Gallagher, 2012). Estos estudios ofrecen una perspectiva útil para enmarcar mensajes de salud sobre Prevención COVID-19. Parece que los mensajes de salud destinado a alentar a las personas a participar en comportamientos preventivo del COVID-19 deben enmarcarse en términos de ganancias, como "Si te lavas las manos correctamente / seguir la política de distanciamiento social / adherirse a la estadía en el hogar política, aumentará las posibilidades de usted y su familia que tiene una vida larga y saludable ".

\section{Optimismo y exceso de confianza}

Las personas muestran un optimismo poco realista sobre su vulnerabilidad frente a un amplio conjunto de resultados negativos (Weinstein, 1980), y a menudo se ven a sí mismos expuestos a un riesgo menor al promedio frente a posibles resultados negativos. El sesgo de optimismo es la tendencia de las personas a estimar la probabilidad de resultados futuros positivos como mayor que el promedio y resultados negativos futuros como menores que el promedio. Esto puede llevar a las personas a tomar involuntariamente riesgos demasiado “Visión de Futuro" Año 18, Volumen No 25 № 2, Edición Especial-III Congreso Regional de Economía del Norte Grande-Pág 31-55 URL de la Revista: http://visiondefuturo.fce.unam.edu.ar/index.php/visiondefuturo/index

URL del Documento: https://visiondefuturo.fce.unam.edu.ar/index.php/visiondefuturo/issue/view/20 
altos con su propia salud, mayores de lo que los que tomarían si fueran conscientes del riesgo objetivo aparejado a dichas conductas. Esto puede ayudar a explicar una amplia gama de comportamientos frente al riesgo, incluidos aquellos relacionados con la salud. Por ejemplo, un estudio reveló que los fumadores subestimaron su riesgo de desarrollar cáncer de pulmón en comparación con el de otros fumadores e incluso no fumadores (Weinstein, 2005). Las personas entienden la existencia del riesgo de contraer COVID-19 resultante de comportamientos subóptimos, como no lavarse las manos o no adherirse al distanciamiento social, pero es probable que crean que son menos propensos a contagiarse de COVID-19 que otras personas o pares, incluso si sus pares se adhieren a las prácticas preventivas. Proporcionar información sobre comparación entre pares o comunicar los riesgos con precisión pueden ser útiles para abordar el optimismo y sesgo de exceso de confianza. Además, informar lo que ha sucedido a individuos o poblaciones que se consideran pares pueden persuadir a las personas a adherirse a los comportamientos preventivos (Matjasko, 2016). Por ejemplo, los adolescentes pueden involucrarse más en la prevención de COVID19 si son conscientes de que una celebridad adolescente se contrajo COVID-19.

\section{Comportamiento de manada e influencia social}

Las normas sociales y el comportamiento de amigos, miembros de la familia y colegas afectan los comportamientos. El comportamiento de manada ocurre cuando las personas consideran un cierto comportamiento como bueno o malo según el comportamiento de otras personas e imitan sus comportamientos observados (Ariely, 2008). Esta característica del comportamiento humano está bien establecida en varios campos, particularmente economía y finanzas (Raafat, 2009). Una implicación de este comportamiento es que, si una política tiene como objetivo alentar a las personas a tomar una decisión de salud, entonces debe informarse a las personas sobre el comportamiento de otras personas y sus compañeros. En un experimento del mundo real realizado sobre cumplimiento tributario en Minnesota, una de las intervenciones informó a las personas que más del $90 \%$ de los habitantes de Minnesota habían pagado sus impuestos; esta tuvo un efecto significativo en el cumplimiento tributario en comparación con otras intervenciones (Coleman, 2007). Para inducir a las personas a adherirse a política de distanciamiento social, las intervenciones deberían llamar la atención a lo que otras personas están haciendo. Por ejemplo, decirle a la gente que "la mayoría de las personas en tu ciudad vecina o provincia están siguiendo el distanciamiento social / política de quedarse en casa" puede aumentar la adhesión a la política de distanciamiento social.

Los sesgos y heurísticas previamente presentados son comunes a los seres humanos, en general o en promedio, pero no deben ignorarse que factores culturales, como las

\footnotetext{
“Visión de Futuro" Año 18, Volumen N²5 N², Edición Especial-III Congreso Regional de Economía del Norte Grande-Pág 31-55 URL de la Revista: http://visiondefuturo.fce.unam.edu.ar/index.php/visiondefuturo/index

URL del Documento: https://visiondefuturo.fce.unam.edu.ar/index.php/visiondefuturo/issue/view/20

ISSN 1668 - 8708 - Versión en Línea

E-mail: revistacientifica@fce.unam.edu.ar
} 
diferencias en la forma en que las personas, y en particular los diferentes grupos de edad, interactúan pueden explicar parte de las tasas de infección y mortalidad tanto dentro como fuera de los países. En este sentido, Platteau y Verardi (2020) utilizan simulaciones para mostrar que las medidas que Bélgica debería tomar al reabrir su economía serían más moderadas si tuvieran los mismos patrones de interacción que Alemania, y más estrictas si tuvieran los patrones de interacción de Italia. Una lección clave es que no existe una solución única que se pueda aplicar a todos los países, o incluso a todas las regiones dentro de un país.

\section{CONCLUSIÓN}

Las fuentes de heterogeneidad espacial y sectorial ofrecen el potencial de segmentación de tratamientos que permitan reducir los impactos negativos de las medidas de distanciamiento más homogéneas y centralizadas. Sin embargo, existe incertidumbre acerca de los criterios de clasificación y parametrización relevantes.

Una posibilidad a explorar consiste es establecer los criterios de clasificación considerando al menos los siguientes aspectos: a) riesgo de infección por exposición en lugar de trabajo, b) riesgo de muerte por edad y sexo, c) localización espacial, d) necesidades económicas del grupo de riesgo y e) situación epidemiológica local. Con estos criterios se podría ejecutar un programa de cierres o restricciones temporales según ubicación y tiempo para cada sector de actividad económica. La viabilidad de este enfoque requiere primero cierta maduración del proceso bajo estudio y el análisis de datos para poder estimar, con una precisión aceptable, los riesgos de contagio y de muerte y los impactos económicos sectoriales.

Nuestra agenda incluye un esfuerzo de desarrollo desde una perspectiva regional periférica de las posibilidades de segmentación y de adecuación de políticas para reducir los costos durante y post pandemia. Este análisis incluye también abordar el estudio de aspectos epidemiológicos, como la estimación de los riesgos de contagio y muestre con variabilidad geográfica.

En este trabajo, además, se presentan aspectos estudiados por la economía del comportamiento, que pueden ser relevantes a la hora de diseñar programa de cierres o restricciones de circulación intermitentes, relacionados a la forma de informarlos a la sociedad y de incentivar su acatamiento.

Finalmente, cabe mencionar que el arribo de vacunas efectivas será un componente nuevo que deberá incluirse en el análisis, ya que cambiará las estimaciones de los riesgos

\footnotetext{
“Visión de Futuro" Año 18, Volumen No 25 N² 2, Edición Especial-III Congreso Regional de Economía del Norte Grande-Pág 31-55 URL de la Revista: http://visiondefuturo.fce.unam.edu.ar/index.php/visiondefuturo/index

URL del Documento: https://visiondefuturo.fce.unam.edu.ar/index.php/visiondefuturo/issue/view/20

ISSN 1668 - 8708 - Versión en Línea

E-mail: revistacientifica@fce.unam.edu.ar
} 
efectuadas previamente en ausencia de vacuna. Tal cambio dependerá tanto de la eficacia de la propia vacuna como de la estrategia de vacunación aplicada.

\section{REFERENCIAS}

Albanesi, S., R. Gihleb, J. Kim y J. Huo (2020). Household Insurance and The Macroeconomic Impact of the Novel Corona Virus. VMACS Seminar, June.

Albrieu, R. (2020). Evaluando las oportunidades y los límites del teletrabajo en Argentina en tiempos del COVID-19. CIPPEC. Programa de Desarrollo Económico.

Ariely, D. (2008). Predictably irrational. Harper Collins.

Bodenstein, M, Corsetti, G y Guerrieri, L. (2020). Social Distancing and Supply Disruptions in a Pandemic. London, Centre for Economic Policy Research. Disponible en https://cepr.org/active/publications/discussion_papers/dp.php?dpno=14629

Coleman, S. (2007) The Minnesota income tax compliance experiment: replication of the social norms experiment. Disponible en https://ssrn.com/abstract=1393292.

Dillard A.J., McCaul, K.D. y Klein, W.M. (2006) Unrealistic optimism in smokers: Implications for smoking myth endorsement and self-protective motivation. J Health Commun. 11(S1):93-102.

Eichenbaum, Martin S., Rebelo, S. y Trabandt, Mathias (2020). The Macroeconomics of Epidemics. NBER Working Paper No. 26882.

Ferguson, NM, D. Laydon, G. Nedjati-Gilani, N. Imai, K Ainslie, M. Baguelin, S. Bhatia, A. Boonyasiri, Z. Cucunubá, G. Cuomo-Dannenburg, and A. Dighe (2020). Impact of nonpharmaceutical interventions (NPIs) to reduce COVID-19 mortality and healthcare demand. March 2020. Imperial College COVID-19 Response Team.

Fernández-Villaverde, Jesús and Charles J. Jones (2020). Estimating and Simulating a SIRD Model of COVID-19 for Many Countries, States, and Cities. NBER Working Paper No. 27128.

Gallagher, K.M. y Updegraff, J.A. (2012). Health Message Framing Effects on Attitudes, Intentions, and Behavior: A Meta-analytic Review. Ann. behav. med. 43, 101-116.

Glover, A., J. Heathcote, D. Krueger, and J. V. Ríos-Rull (2020). Health versus Wealth: On the Distributional Effects of Controlling a Pandemic. NBER Working Paper No. 27046.

John, L.K., Loewenstein, G., Troxel, A.B., Norton, L., Fassbender, J.E., Volpp, K.G. (2011) Financial incentives for extended weight loss: a randomized, controlled trial. J Gen Intern Med. 26(6):621-6.

Jordan, R. E., Adab, P., \& Cheng, K. K. (2020). Covid-19: risk factors for severe disease and death.

\footnotetext{
"Visión de Futuro" Año 18, Volumen N²5 N², Edición Especial-III Congreso Regional de Economía del Norte Grande-Pág 31-55 URL de la Revista: http://visiondefuturo.fce.unam.edu.ar/index.php/visiondefuturo/index

URL del Documento: https://visiondefuturo.fce.unam.edu.ar/index.php/visiondefuturo/issue/view/20

ISSN 1668 - 8708 - Versión en Línea

E-mail: revistacientifica@fce.unam.edu.ar
} 
Laibson, D. (1997) Golden Eggs and Hyperbolic Discounting. The Quarterly Journal of Economics, Volume 112, Issue 2, May 1997, Pages 443-478.

Li, X., Xu, S., Yu, M., Wang, K., Tao, Y., Zhou, Y., ... \& Zhang, C. (2020). Risk factors for severity and mortality in adult COVID-19 inpatients in Wuhan. Journal of Allergy and Clinical Immunology.

Linnemayr, S., Stecher, C., Mukasa, B. (2017) Behavioral economic incentives to improve adherence to antiretroviral medication. AIDS (Londres, Inglaterra). 31(5):719.

Loewenstein, G., Asch, D.A., Friedman, J.Y., Melichar, L.A., Volpp, K.G. (2012) Can behavioural economics make us healthier? BMJ. 344: e3482.

Luoto, J., Carman, K.G. (2014) Behavioral economics guidelines with applications for health interventions. Washington: Inter-American Development Bank.

Malani, M., S. Soman, S. Asher, P. Novosad, C. Imbert, V. Tandel, A. Agarwal, A. Alomar, A. Sarker, D. Shah, D. Shen, J. Gruber, S. Sachdeva, D. Kaiser y L. Bettencourt (2020). Adaptive control of covid-19 outbreaks in india: local, gradual, and trigger-based exit paths from lockdown. NBER Working Paper No. 27532.

Martínez Villarreal, D., Rojas Méndez, A. M. y Scartascini, C. (2020) La economía del comportamiento puede ayudar a combatir el coronavirus. Resumen de Políticas del BID; 334. Banco Interamericano de Desarrollo.

Matjasko JL, Cawley JH, Baker-Goering MM, Yokum DV. (2016) Applying Behavioral Economics to Public Health Policy: Illustrative Examples and Promising Directions. Am J Prev Med. 50(5 Suppl 1): S13-S19.

Montenovo, L., Jiang, X., Rojas, F. L., Schmutte, I. M., Simon, K. I., Weinberg, B. A., \& Wing, C. (2020). Determinants of disparities in covid-19 job losses (No. w27132). National Bureau of Economic Research.

O'Donoghue, T. y Rabin, M. (1999) Doing It Now or Later. American Economic Review, 89 (1): 103-124.

Platteau, J-P. y Verardi, V. (2020) Because culture matters, there is no one-size-fits-all strategy for exit from Covid-19 lockdowns. Disponible en: https://voxeu.org/article/culture-andlockdown-exit-strategies

Raafat, R.M., Chater, N., Frith, C. (2009) Herding in humans. Trends Cognit Sci. 13(10):4208.

Sannigrahi, S., Pilla, F., Basu, B., Basu, A. S., \& Molter, A. (2020). Examining the association between socio-demographic composition and COVID-19 fatalities in the European region using spatial regression approach. Sustainable cities and society, 62, 102418.

\footnotetext{
"Visión de Futuro" Año 18, Volumen No 25 N 2, Edición Especial-III Congreso Regional de Economía del Norte Grande-Pág 31-55 URL de la Revista: http://visiondefuturo.fce.unam.edu.ar/index.php/visiondefuturo/index

URL del Documento: https://visiondefuturo.fce.unam.edu.ar/index.php/visiondefuturo/issue/view/20

ISSN 1668 - 8708 - Versión en Línea

E-mail: revistacientifica@fce.unam.edu.ar
} 
Soofi, M., Najafi, F. y Karami-Matin, B. (2020). Using Insights from Behavioral Economics to Mitigate the Spread of COVID-19. Appl Health Econ Health Policy 18, 345-350.

Stock, J. H. (2020). Data Gaps and the Policy Response to the Novel Coronavirus. NBER Working Paper No. 26902.

Tversky A, Kahneman D. (1979) Prospect theory: an analysis of decision under risk. Econometrica 47(2):263-91.

Sun, Y., Hu, X., \& Xie, J. (2020). Spatial inequalities of COVID-19 mortality rate in relation to socioeconomic and environmental factors across England. Science of The Total Environment, 143595.

Weinstein, N.D., Marcus, S.E., Moser, R.P. (2005) Smokers' unrealistic optimism about their risk. Tob Control. 14(1):55-59.

\section{RESUMEN BIBLIOGRÁFICO}

\section{Lucas Ferrero}

Profesor Titular Economía Monetaria y Macroeconomía II en Facultad de Ciencias Económicas de la Universidad Nacional del Nordeste. Doctor en Economía (Universidad Bocconi), Licenciado en Economía (UNNE). Interés en Economía Política y Desarrollo Económico.

\section{Carlos Matías Hisgen}

Profesor Titular Econometría, JTP de Estadística II en Facultad de Ciencias Económicas de la Universidad Nacional del Nordeste. Doctor en Estadística (Universidad de Santiago de Compostela), Licenciado en Economía (UNNE). Interés en Microeconometría Aplicada y Desarrollo Económico.

\section{Diego Ramón Álvarez}

Profesor Titular de Matemática para Economistas en Facultad de Ciencias Económicas de la Universidad Nacional del Nordeste. Doctor en Economía Agraria (Universidad de Nebraska), Licenciado en Economía (UNNE). Interés en Economía Agraria y Desarrollo Económico.

\footnotetext{
"Visión de Futuro" Año 18, Volumen No 25 № 2, Edición Especial-III Congreso Regional de Economía del Norte Grande-Pág 31-55 URL de la Revista: http://visiondefuturo.fce.unam.edu.ar/index.php/visiondefuturo/index

URL del Documento: https://visiondefuturo.fce.unam.edu.ar/index.php/visiondefuturo/issue/view/20

ISSN 1668 - 8708 - Versión en Línea

E-mail: revistacientifica@fce.unam.edu.ar
} 